\title{
Physicochemical properties of lacquer berries and decolorization of lacquer wax by physical adsorption and UV irradiation
}

\author{
Chengzhang Wang ${ }^{1,2,3^{*}}$, Yanhe Dong ${ }^{1,2}$, Hongxia Cheng ${ }^{1,2}$, Yuanfeng $\mathrm{He}^{1,2}$, Jianzhong Ye $\mathrm{e}^{1,2}$, \\ Hao Zhou ${ }^{1,2,3}$ \\ ${ }^{1}$ Institute of Chemical Industry of Forest Products, CAF, Nanjing, China \\ ${ }^{2}$ Key and Open Laboratory on Forest Chemical Engineering, SFA, Nanjing, China \\ ${ }^{3}$ Institute of New Technology of Forestry, CAF, Beijing, China \\ Email: ${ }^{*}$ wangczlhs@sina.com
}

Received 17 March 2013; revised 3 May 2013; accepted 17 May 2013

Copyright (C) 2013 Chengzhang Wang et al. This is an open access article distributed under the Creative Commons Attribution License, which permits unrestricted use, distribution, and reproduction in any medium, provided the original work is properly cited.

\begin{abstract}
Physicochemical properties of No.1 - No.6 lacquer berries were investigated from different origins. The Japan Showafuku (No.1) was the best cultivar of Rhus succedaneum, the size of the berry of it was near 3 - 4 folds, which was bigger than the Chinese cultivars (No.4 - No.6) of Rhus vernicifera et al. It had more than $5 \% \sim 10 \%$ of lacquer wax in pericard, and contained less than $6 \%-8 \%$ of lacquer oil in seed. No.1 had lower acid value (A.V) and iodine value (I.V); the key factors for this were cultivar and its growing environment. The principal constituents of lacquer waxes of No.1 - No.6 were triglycerides of fatty acids with total saturated fatty acids (TSFA) of $75 \%-82.7 \%$, total unsaturated fatty acids (TUSFA) of $15.1 \%-20 \%$, and total dibasic acids (TDBA) of 5\%. The CIEL a b system and Hunter whiteness formula were used to evaluate the bleaching effect on lacquer wax by physical adsorption and ultraviolet (UV) irradiation. The optimal conditions of physical decoloration were determined for activated carbon: kieselguhr $=3: 2(\mathrm{~g} / \mathrm{g})$ as adsorbent, a ratio of $1: 20$ $(\mathrm{g} / \mathrm{mL})$ for lacquer wax to petroleum ether, bleaching $30 \mathrm{~min}$ at $80^{\circ} \mathrm{C}$. UV light achieved a good bleaching effect irradiated at $60^{\circ} \mathrm{C}$ for 60 hrs. UV irradiation definitely changed relative contents of fatty acids, TUSFA and TDBA decreased from $19.617 \%$ to $11.022 \%$ and $4.379 \%$ to $2.017 \%$ respectively, while TSFA could be raised from $76.462 \%$ to $86.077 \%$, however, the mechanism of UV irradiation was still unclear and should be investigated in the future.
\end{abstract}

${ }^{*}$ Corresponding author.
Keywords: T. vernicifera; Lacquer Berries; Lacquer Wax; Physical Decolorization; UV Irradiation

\section{INTRODUCTION}

Lacquer tree belongs to the family of Anacardiaceae. There are more than 73 general kinds and more than 600 different species of lacquer trees all over the world. Most of them grow in the subtropical regions of southeast Asia. $[1,2]$. Rhus succedanea $\mathrm{L}$. is a cultivated tree, it was originally introduced to Japan from China at the end of the 16th century AD via Ryukyu islands. About 30 species among these trees can produce as much as 1.5 million tons of lacquer berry per year, which contain large amounts of wax, while lacquer berry has not been processed and utilized until now [3].

Lacquer wax has a wide range of applications such as food, cosmetics, medicines, electronic photography toner, etc. it has been used as edible vegetable oil in China minority, which can prevent stomach diseases, it is also the excellent nutrition for puerpera. Japanese scholars develop a kind of coffee drinks of lacquer berry by baking lacqer seed, which is a benefit for digestion.

Lacquer wax is an important fatty resource from the mesocarp of the berries of lacquer tree, i.e., T. verniciflua, T. sylvestris Sieb and rhus trichocarpa in China. Its principal constituents are triglycerides of fatty acids, long-chain aliphatic alcohol and pigments, and compared with the Japan wax, it has a similar physical properties and chemical constituents in the main fatty acids particularly. Japan wax is made from the berry of Rhus succedanea $L$ (hazenoki in Japanese). The difference lies in the cultivars and planting environment. For containing a special ingredient which is known as "Japan acid", 
Japan wax, as a kind of high-grade fatty acid, exhibits its excellent properties, such as tackiness, releasability, and low iodine value as well as $100 \%$ natural in origin and nontoxic to human body [4-6], however lacquer wax from China might have a much lower content than the Japan acid [7].

As pigments are the key factors to involve the quality of lacquer wax, more researches focus on the discoloration of lacquer seed oils and lacquer wax recently. Adsorbents or chemical agents are used to decolorize and bleach lacquer wax, activated charcoal or acid clay is added directly to molten crude wax and then the adsorbent is separated by filtration. But research has found that activated carbon had poor bleaching, what's more, powdered activated carbon was very difficult to filtrate [8]. A traditional method to produce Japan wax is to remove the pigments with the aid of sun's ray $[9,10]$, however, it wholly depends on weather conditions and time-consuming. Due to its low yield and labor-intensiveness, this old-fashioned method is uneconomical and inefficient.

It is suggested that UV ray irradiation may serve as an alternative and effective decoloration method without depending on weather conditions. Meguro S et al. had investigated physical properties, major fatty acid contents and seasonal variations of some chemical constituents of the Japan wax [11-13], however, very few literatures reported the bleaching effection of physical adsorption and UV light on lacquer wax, particularly in physico-chemical properties of lacquer wax. The aim of this paper was to investigate the physicochemical properties of different species and discoloration process of lacquer wax from lacquer berries via physical adsorption and UV irradiation.

\section{MATERIALS AND METHODS}

\subsection{Lacquer Berries and Chemicals}

No.1 - No.6 samples are the berries of lacquer tree. No.1 sample was collected from japan native Showafuku cultivar of Rhus succedanea $L$, grafted over 10 years in Kyushu area in japan. No.2 sample was from the introduced Showafuku cultivar of Rhus succedanea $L$ from japan, grafted about 3 - 4 years in Lindu county, Jiangxi province, No.3 sample also from the introduced Showafuku cultivar, but seeded about $8-10$ years in the same plantation in Jiangxi province. No.4 sample was from local cultivar of T. vernicifera seeded over 25 years in Enshi area, Hubei province, No.5 sample was from local cultivar of T. sylvestris Sieb seeded over 20 years in Ankang area, Shanxi province, and No.6 sample was from local cultivar of rhus trichocarpa seeded over 20 years in Lujiang area, Yunnan province. All samples were collected in November, 2012 , then dried at $45^{\circ} \mathrm{C}$ for
$10 \mathrm{~h}$ in the oven. The dried fruit, with less than $7.0 \%$ of water, were crushed to remove the husks and seed kernel, the remained pulp was grounded into powder and stored in dryness and darkness.

Standard of methyl ethers of fatty acids were purchased from Shanghai An Pu Chemical Reagent Co. Ltd. Activated carbon, kieselguhr and solvents were purchased from Nanjing chemical industries company, Ltd.

\subsection{Preparation of Lacquer Wax}

The pulp powder from No.5 sample was extracted by using petroleum ether $\left(60^{\circ} \mathrm{C}-90^{\circ} \mathrm{C}\right)$ with solid-liquid ratio of $1: 20(\mathrm{~g} / \mathrm{mL})$, at $80^{\circ} \mathrm{C}$ for $60 \mathrm{~min}$, twice then to combinate the extraction solution, filtered and condensed in vacuum, the residue yielded raw lacquer wax with green color.

\subsection{Physical Discoloration of Lacquer Wax}

Single factors experiments and $\mathrm{L}_{9}\left(3^{4}\right)$ orthogonal experiments of three factors (ratio of raw wax to solvent $(\mathrm{g} / \mathrm{mL})$, discolor temperature and times) were designed. $10 \mathrm{~g}$ of raw wax was dissolved in petroleum ether each time, water was added for keeping a special temperature. After filtrating, the filtrate was condensed under vacuum, the residue was cooled and obtained solid of lacquer wax. The whiteness of the lacquer wax was then measured by Hunter completely whiteness formula.

\subsection{UV Irradiation of Lacquer Wax}

$10 \mathrm{~g}$ of raw lacquer wax from sample 5 was placed in a petri dish $(6 \mathrm{~cm}$ inside diameter (ID) $\times 1.1 \mathrm{~cm}$ height $(\mathrm{H})$ ), and irradiated under a UV lamp of $400 \mathrm{~W}$ at 360 $\mathrm{nm}$. The irradiated time change from 10 to $80 \mathrm{~h}$ at $50^{\circ} \mathrm{C}$, $60^{\circ} \mathrm{C}$ and $70^{\circ} \mathrm{C}$, respectively, the whiteness of the samples was measured after solidification by Hunter completely whiteness formula.

\subsection{Detection Method of Whiteness}

Under the Huntersystem, WSC-S colorimeter was preheated for $30 \mathrm{~min}$. As the chromaticity of L, a, b of lacquer wax was measured, the hunter whiteness could be calculated by using Hunter completely whiteness formula.

$$
\mathrm{W}=100-\left((100-\mathrm{L})^{2}+\mathrm{a}^{2}+\mathrm{b}^{2}\right)^{1 / 2}
$$

W-Hunter whiteness of the sample; L-Hunter lightness index; $\mathrm{a}, \mathrm{b}$ - Hunter chromaticity.

WSC-S colorimeter was used to characterize the discoloration effect of the lacquer wax, while chromaticity values were used to represent the change of the pigments. 


\subsection{Determination of Chemical Constituents of Fatty Acids of Lacquer Wax}

The constituents of fatty acids of lacquer wax should be analysized by GC-MS equipped with a SE-30 capillary column. The injector temperature was $280^{\circ} \mathrm{C}$, gas chromatography oven was programmed to provide a constant temperature with an increased rate of $10^{\circ} \mathrm{C}$ per min from $110^{\circ} \mathrm{C}$ to $220^{\circ} \mathrm{C}, 10 \mathrm{~min}$ at $110^{\circ} \mathrm{C}$ and $18 \mathrm{~min}$ at $220^{\circ} \mathrm{C}$, Helium was used as carrier gas with a flow rate of 1 $\mathrm{mL} / \mathrm{min}$. The mass spectrometer was operated in $70 \mathrm{eV}$ EI mode scanning from 29.0 to $450.0 \mathrm{u}$ in the full-scan acquisition mode. The EI source with a temperature of $230^{\circ} \mathrm{C}$. Identification of the constituents of the fatty acids was based on computer matching by commercial mass spectra (NIST and WILEY Mass Spectral Search Program). The relative content of the constituents was calculated and expressed as a peak area percentage computed by the chemstation, accompanying software.

\section{RESULTS AND DISCUSSION}

\subsection{Physical Properties of Lacquer Berries}

No.1 - No.3 Showafuku cultivar of Rhus succedanea $L$ are planted in tropical regions of south of japan and china, while No.4 - No.6 local cultivars from T. verniciflua, T. sylvestris Sieb and rhus trichocarpa grow in different regions in central and westnorth of china, as the difference of cultivars and their growing environment, lacquer tree of Showafuku cultivar maily produce fruits, and no lacquer sap could be secreted out, especially in grafted lacquer tree. However, lacquer tree of No.4 No.6 cultivars are mainly used to secrete sap, therefore lacquer tapping have great effect on physical quality of lacquer berry, i.e., the size and outcome of lacquer berry, as well wax content.

Lacquer berries are comprised of epicarp, mesocarp and seed, among which lacquer wax mainly present in the mesocarp. Grafted Showafuku was the best cultivar, which size of berry not only was near 3 - 4 folds bigger than local seeded cultivars in china, but also had more $5 \% \sim 10 \%$ of lacquer wax in pericard, and contained less $6 \% \sim 8 \%$ of lacquer oil.

Physical parameters of wax in lacquer berry from No.1 - No.6 samples had a similar for peroxide value (P.V) 5 10 and saponification value (S.V) 207.13 - 216.30, however had a complete distinct for melt point (M.P) 46 $54^{\circ} \mathrm{C}$, acid value (A.V) $10.2-88.3$, and iodine value (I.V) 10.3 - 33.6 in Table 1. Japan Showafuku was best with higher M.P and lower A.V, I.V, P.V and S.V, the reasons maybe suggested that china lacquer berry contained more unsaturated fatty acids and free fatty acids, it further to show cultivars and their growing environment are key factors to impact physical properties of wax.

\subsection{Chemical Constituents of Wax in Lacquer Berries}

The principal constituents of lacquer waxes form No.1 No.6 are a few of free fatty acid, higher aliphatic alcohols, and most of triglycerides of fatty acids, In which palmitic acid account for $55.1 \%-71.7 \%$, Oleic acid for $11.5 \%-17.3 \%$, stearic acid for $5.9 \%-12.6 \%$, eicosanoic acid for $1.7 \%-7.8 \%$, and less $3 \%$ docosanoic acid, the total TSFA accounted for $75 \%-82.7 \%$, however TUSFA for $15.1 \%-20 \%$, in which TDBA just contained lower 5\% in Table 2.

Although No.1 - No.3 also came from rhus succedaneum, No.1 contained much higher TSFA, particular in TDBA, which was why Japan wax known to have good viscosity, permeability and insulation characteristics, it also suggested that growing environment could be key factor to contribute.

\section{PHYSICAL DISCOLORATION OF LACQUER WAX}

\subsection{Lacquer Wax}

Lacquer wax was made from No.5 sample, single factors experiments were carried out for physical discoloration

Table 1. The constituents of lacquer berries and physical properties of No.1 - No.6 samples (100 grain berries).

\begin{tabular}{|c|c|c|c|c|c|c|c|c|c|c|}
\hline $\begin{array}{l}\text { Samples } \\
\text { No. }\end{array}$ & $\begin{array}{l}\text { weight } \\
\text { (g) }\end{array}$ & $\begin{array}{l}\text { pericarp in } \\
\text { berry }(\%)\end{array}$ & $\begin{array}{c}\text { seed in } \\
\text { berry }(\%)\end{array}$ & $\begin{array}{c}\text { wax in } \\
\text { berry }(\%)\end{array}$ & $\begin{array}{c}\text { seed oil } \\
\text { in berry }(\%)\end{array}$ & $\begin{array}{l}\text { melt point } \\
\text { of wax }\left({ }^{\circ} \mathrm{C}\right)\end{array}$ & $\begin{array}{l}\text { acid value of wax } \\
(\mathrm{KOH}, \mathrm{mg} / \mathrm{g})\end{array}$ & $\begin{array}{l}\text { iodine value of } \\
\text { wax } \mathrm{g} / 100 \mathrm{~g}\end{array}$ & $\begin{array}{l}\text { f peroxide value of } \\
\text { wax }(\mathrm{mmol} / \mathrm{kg})\end{array}$ & $\begin{array}{c}\text { saponification } \\
\text { value of wax } \\
\mathrm{KOH}, \mathrm{mg} / \mathrm{g}\end{array}$ \\
\hline No.1 & 15.72 & 51.37 & 48.63 & 26.27 & 0.33 & $50.0-53.5$ & 10.2 & 10.3 & 7.5 & 207.13 \\
\hline No. 2 & 16.14 & 54.48 & 45.52 & 31.25 & 2.35 & $48.6-51.8$ & 55.4 & 15.1 & 6.1 & 208.90 \\
\hline No.3 & 11.95 & 52.21 & 47.79 & 27.01 & 3.80 & $48.5-50.2$ & 40.4 & 15.1 & 6.9 & 208.90 \\
\hline No.4 & 5.48 & 45.84 & 54.16 & 20.84 & 8.36 & $46.5-48.5$ & 47.1 & 33.3 & 8.5 & 216.30 \\
\hline No.5 & 5.76 & 44.63 & 55.36 & 21.32 & 7.88 & $46.5-48.5$ & 88.3 & 33.6 & 8.78 & 213.10 \\
\hline No.6 & 4.72 & 42.48 & 57.52 & 22.93 & 6.57 & $49.5-51.3$ & 73.2 & 26.6 & 7.3 & 212.70 \\
\hline
\end{tabular}


Table 2. The constituents and contents of fatty acids of No.1 - No.6 samples by GC-MS.

\begin{tabular}{|c|c|c|c|c|c|c|c|c|}
\hline \multirow{3}{*}{$\begin{array}{c}\text { Peak } \\
1\end{array}$} & \multirow{2}{*}{\multicolumn{2}{|c|}{ Constutites of main fatty acids }} & \multicolumn{6}{|c|}{ Relative content of fatty acids in samples of No.1 - No.6 } \\
\hline & & & \multirow{2}{*}{$\begin{array}{l}\text { No.1 } \\
0.107\end{array}$} & \multirow{2}{*}{$\begin{array}{l}\text { No.2 } \\
0.283\end{array}$} & \multirow{2}{*}{$\begin{array}{l}\text { No.3 } \\
0.216\end{array}$} & \multirow{2}{*}{$\begin{array}{l}\text { No.4 } \\
0.267\end{array}$} & \multirow{2}{*}{$\begin{array}{l}\text { No.5 } \\
0.903\end{array}$} & \multirow{2}{*}{$\begin{array}{l}\text { No.6 } \\
0.134\end{array}$} \\
\hline & Myristic acid & $\mathrm{C} 14: 0$ & & & & & & \\
\hline 2 & Pentadecanoic acid & $\mathrm{C} 15: 0$ & 0.090 & 0.220 & 0.213 & 0.170 & 0.437 & 0.039 \\
\hline 3 & Hexadecenoic acid & C16:1 & 0.093 & 0.215 & 0.130 & 0.123 & 0.223 & 0.186 \\
\hline 4 & Palmitic acid & $\mathrm{C} 16: 0$ & 71.722 & 57.989 & 58.486 & 55.156 & 59.743 & 67.420 \\
\hline 5 & Heptadecanoic acid & $\mathrm{C} 17: 0$ & 0.088 & 0.635 & 0.184 & 0.523 & 0.334 & 0.062 \\
\hline 6 & Linoleic acid & $\mathrm{C} 18: 2$ & 0.204 & 0.389 & 0.467 & 0.264 & 0.839 & 0.241 \\
\hline 7 & Oleic acid & C18:1 & 11.505 & 13.133 & 14.317 & 17.263 & 14.248 & 14.132 \\
\hline 8 & Octadecanoic acid & $\mathrm{C} 18: 0$ & 7.719 & 11.544 & 12.375 & 12.566 & 11.447 & 5.930 \\
\hline 9 & Hexadecanedioic acid & $\mathrm{C} 16 \mathrm{~d}+$ & 0.192 & 0.262 & 0.130 & 0.452 & 0.841 & 0.145 \\
\hline 10 & Eicosanoic acid & $\mathrm{C} 20: 0$ & 3.036 & 4.109 & 3.846 & 5.764 & 1.696 & 7.796 \\
\hline 11 & Eicosanebioic acid & $\mathrm{C} 20 \mathrm{~d}+$ & 2.230 & 1.235 & 1.477 & 1.824 & 2.752 & 0.312 \\
\hline 12 & Docosanedioic acid & $\mathrm{C} 22 \mathrm{~d}+$ & 2.653 & 0.384 & 1.065 & 1.326 & 0.827 & 0.085 \\
\hline \multirow[t]{4}{*}{13} & Docosanoic acid & $\mathrm{C} 22: 0$ & 3.036 & 0.554 & 0.822 & 0.637 & 0.487 & 0.460 \\
\hline & \multicolumn{2}{|c|}{ Total saturated fatty acids (TSFA) } & 82.762 & 75.334 & 76.142 & 75.083 & 75.047 & 81.841 \\
\hline & \multicolumn{2}{|c|}{ Total unsaturated fatty acids (TUSFA) } & 16.877 & 15.618 & 17.586 & 21.25 & 19.73 & 15.101 \\
\hline & \multicolumn{2}{|c|}{ Total dibasic acids } & 5.075 & 1.876 & 2.672 & 3.602 & 4.42 & 0.542 \\
\hline
\end{tabular}

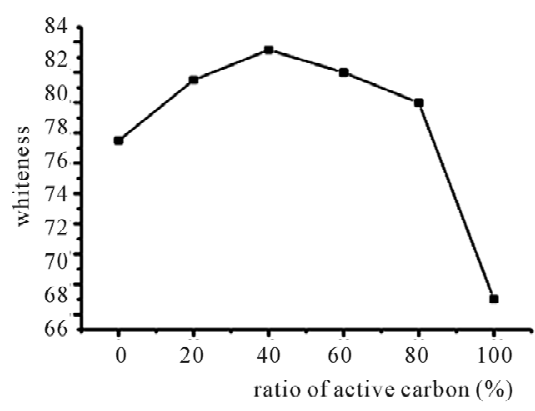

(a)

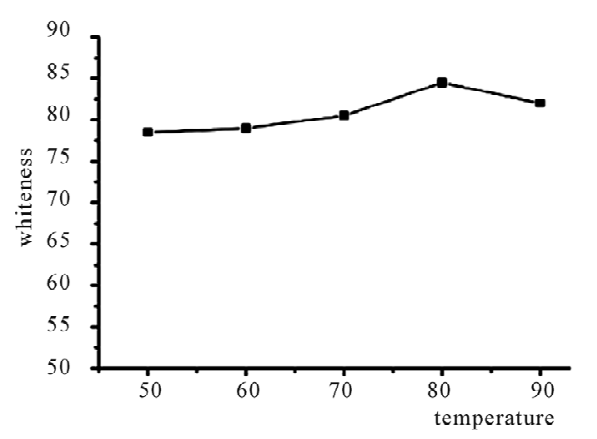

(d)

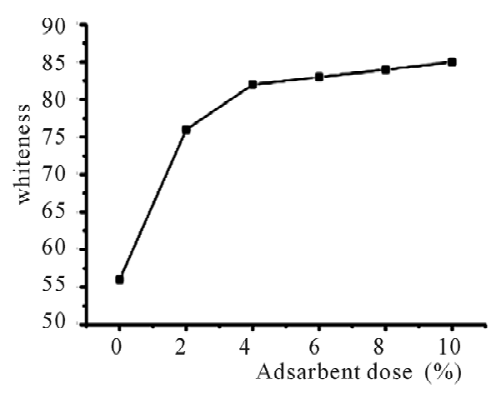

(b)

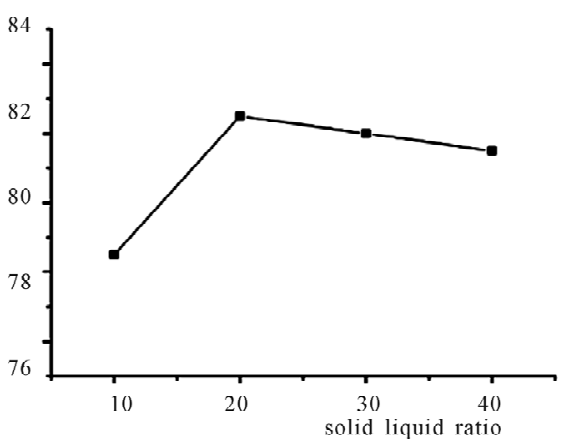

(e)

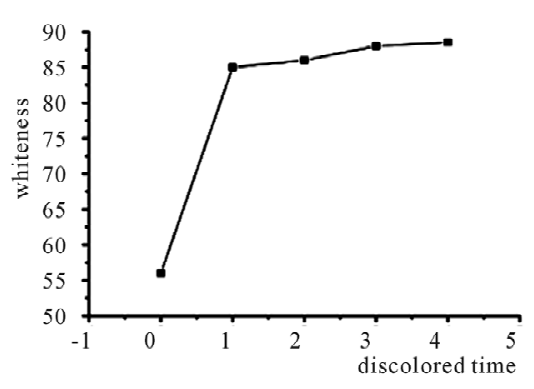

(c)

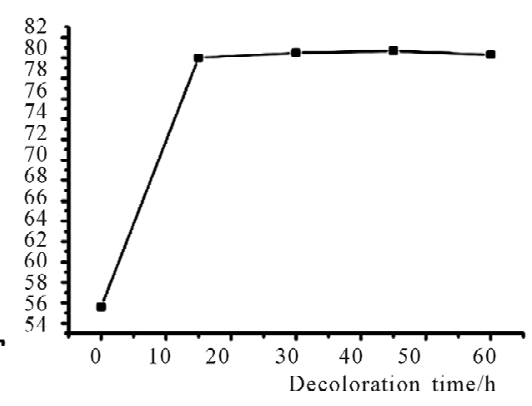

(f)

Figure 1. single factor discoloration experiments by physical adsorption. (a) Optimization for the ratio of activated carbon and kieselguhr; (b) Selection for the adsorbent dose; (c) Selection for the discoloration times; (d) Selection for temperature; (e) Selection for solid-liquid ratio; (f) Selection for discoloration time. 
process of lacquer wax. The optimized decoloration could be reached by a kind of mixed adsorbent with a ratio of activated carbon and kieselguhr 3:2 in Figure 1(a), $5 \%$ doses of the adsorbent weigh to raw lacquer wax in Figure 1(b), discoloration times for twice in Figure 1(c). discoloration temperature at $80^{\circ} \mathrm{C}$ in Figure 1(d), discoloration duration for $30 \mathrm{~min}$ each time in Figure 1(e), and solid-liquid ratio of raw lacquer wax to petroleum ether 1:20 $(\mathrm{g} / \mathrm{mL})$ in Figure 1(f), the whiteness could dramatically be improved after decolorted.

In order to further optimize and validate discoloration process of single factors experiments, the orthogonal experiments were designed by $\mathrm{L}_{9}\left(3^{4}\right)$ of three factors, for instance, solid-liquid ratio of raw wax to solvent $(\mathrm{g} / \mathrm{ml})$ chosed 1:10, 1:20 and 1:30, discoloration time for $30 \mathrm{~min}$, $45 \mathrm{~min}$ and $60 \mathrm{~min}$, and decolor temperature at $70^{\circ} \mathrm{C}$, $80^{\circ} \mathrm{C}$ and $90^{\circ} \mathrm{C}$, respectively. As shown by the data in Table 3, the temperature was the most significant effect for the discoloration process. The best discoloration conditions were optimized as $A_{2} B_{2} C_{1}$ in Table 3. So the optimal conditions chosed petroleum ether as solvent, solidliquid ratio of raw lacquer wax to petroleum ether $1: 20(\mathrm{~g} / \mathrm{mL})$, activated carbon-kieselguhr $=3: 2(\mathrm{~g} / \mathrm{g})$ as adsorbent, which accounted for $5 \%$ weight of raw lacquer wax, kept a temperature of $80^{\circ} \mathrm{C}$ for $60 \mathrm{~min}$, twice. Orthogonal result showed the optimized conditions consistented or similar with single factors experiments, the whiteness of discolored raw wax could rise to 85.36. from the comprehensive analysis above, due to a litter change of the whiteness from $30 \mathrm{~min}$ to $60 \mathrm{~min}$, the discoloration time would be preferred for $30 \mathrm{~min}$, it would be more economical and fast.

\subsection{Discoloration of Lacquer Wax by UV Irradiation}

UV irradiation of lacquer wax was investigated also from No.5 sample. Raw lacquer wax was irradiated under a UV lamp of $400 \mathrm{~W}$ at $360 \mathrm{~nm}$ from $10 \mathrm{hr}$ to $80 \mathrm{hr}$ at 50,60 and $70^{\circ} \mathrm{C}$, respectively. As could be seen from Figure 2, the whiteness of the lacquer wax could go up to 85.36 after UV irradiation. The discoloration time was the most significant factor, the longer the decoloration time was, the better the effecton would be, and discoloration for $60 \mathrm{hrs}$ could achieve a good effect. Temperature had a litter effect on the UV irradiation. Due to melting point of lacquer wax was about $49^{\circ} \mathrm{C}-52^{\circ} \mathrm{C}$, so irradiation temperature of $60^{\circ} \mathrm{C}$ could satisfy well and was preferred.

\subsection{Changes of Chromaticity Values of Discoloration}

The color of lacquer wax was produced by traditional squeezing or solvent extract process, the pigments mainly include chlorophyll, carotene and xanthophyll etc., which are the key factors to affect the quality of lacquer

Table 3. Orthogonal experiments of $\mathrm{L}_{9}\left(3^{4}\right)$ of three factors.

\begin{tabular}{|c|c|c|c|c|c|}
\hline No. & Temperature $\left({ }^{\circ} \mathrm{C}\right)$ & Solid/liquid ratio & Time (min) & Blank rows & Whiteness \\
\hline 1 & $70\left(\mathrm{~A}_{1}\right)$ & $1: 10\left(\mathrm{~B}_{1}\right)$ & $30\left(\mathrm{C}_{1}\right)$ & 1 & 80.02 \\
\hline 2 & $70\left(\mathrm{~A}_{1}\right)$ & $1: 20\left(B_{2}\right)$ & $45\left(C_{2}\right)$ & 2 & 80.10 \\
\hline 3 & $70\left(\mathrm{~A}_{1}\right)$ & $1: 30\left(\mathrm{~B}_{3}\right)$ & $60\left(\mathrm{C}_{3}\right)$ & 3 & 82.05 \\
\hline 4 & $80\left(\mathrm{~A}_{2}\right)$ & $1: 10\left(B_{1}\right)$ & $45\left(\mathrm{C}_{2}\right)$ & 3 & 83.40 \\
\hline 5 & $80\left(\mathrm{~A}_{2}\right)$ & $1: 20\left(B_{2}\right)$ & $60\left(\mathrm{C}_{3}\right)$ & 1 & 85.36 \\
\hline 6 & $80\left(\mathrm{~A}_{2}\right)$ & $1: 30\left(\mathrm{~B}_{3}\right)$ & $30\left(\mathrm{C}_{1}\right)$ & 2 & 84.69 \\
\hline 7 & $90\left(\mathrm{~A}_{3}\right)$ & $1: 10\left(B_{1}\right)$ & $60\left(\mathrm{C}_{3}\right)$ & 2 & 81.81 \\
\hline 8 & $90\left(\mathrm{~A}_{3}\right)$ & $1: 20\left(\mathrm{~B}_{2}\right)$ & $30\left(\mathrm{C}_{1}\right)$ & 3 & 84.84 \\
\hline 9 & $90\left(\mathrm{~A}_{3}\right)$ & $1: 30\left(\mathrm{~B}_{3}\right)$ & $45\left(C_{2}\right)$ & 1 & 82.55 \\
\hline $\mathrm{K} 1$ & 242.17 & 245.23 & 249.55 & 247.93 & $\mathrm{~T}=744.82$ \\
\hline $\mathrm{K} 2$ & 253.45 & 250.30 & 246.05 & 246.60 & -- \\
\hline K3 & 249.20 & 249.29 & 249.22 & 250.29 & -- \\
\hline k1 & 80.72 & 81.74 & 83.18 & 82.64 & -- \\
\hline k2 & 84.48 & 83.43 & 82.02 & 82.20 & -- \\
\hline $\mathrm{k} 3$ & 83.07 & 83.10 & 83.07 & 83.43 & -- \\
\hline
\end{tabular}




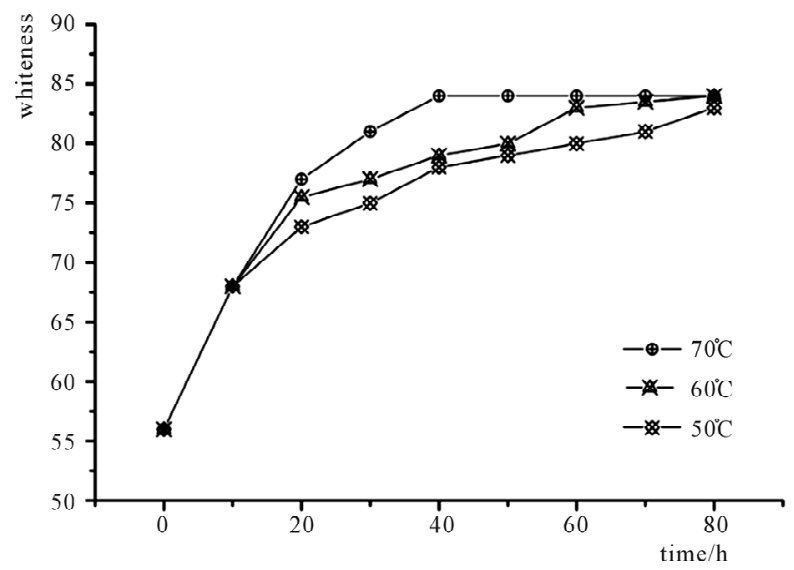

Figure 2. Whiteness change of lacquer wax under UV irradiation.

wax. Adsorbents are capable of adsorbing the pigments, while chemicals, sun's ray or UV light can destroy the structure of the pigment, and thus they may be used to decolorize the pigment in lacquer wax. $a$ and $b$ are the chromaticity values in the Hunter completely whiteness formula, $+a$ represents the redness and - a represents the greenness, while $+\mathrm{b}$ signifies yellowness. Variation trend of chromaticity $\mathrm{a}$ and $\mathrm{b}$ with decoloration time of adsorbent under $60^{\circ} \mathrm{C}$ was shown in Figure 3. The value of a had not changed significantly while $b$ decreased dramatically from 25 to 12 with the extension of the discoloration time, this demonstrated that main carotenoids in the pigment could be adsorbed by the mixed adsorbent of activated carbon-kieselguhr $=3: 2(\mathrm{~g} / \mathrm{g})$.

The variation trend of chromaticity $a$ and $b$ with UV decoloration time at $60^{\circ} \mathrm{C}$ was shown in Figure 4. The changes of the chromaticity values of the lacquer wax was very distinct after UV irradiation, the value of a could decrease to near -1 , it indicated red pigment in lacquer wax could be reduced after 50 min UV irradiation, and $\mathrm{b}$ value decreased to 12 showed that yellow pigment decreased dramatically in 60 min UV irradiation. The reasons suggested that the red and yellow pigments, such as carotene and xanthophyll, contain unsaturated groups in natural pigment, which can absorb the energy of UV visible light, UV light could destroy the structure of double bonds of the pigments in wax, and obtained the white lacquer wax [15].

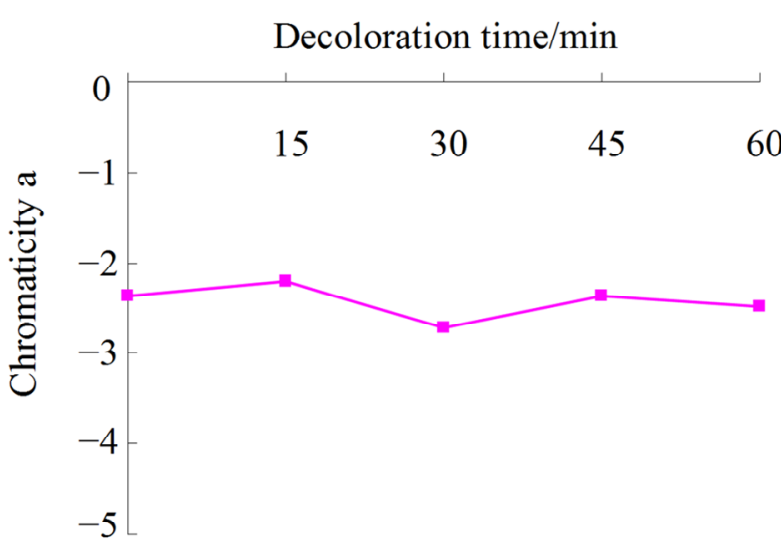

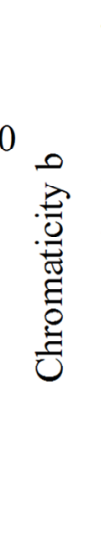

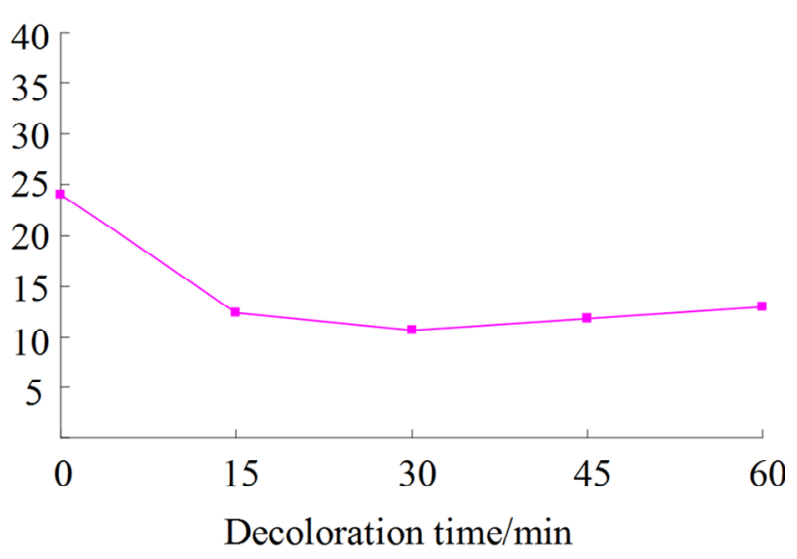

Figure 3. Variation of chromaticity a and b with decoloration time of physical adsorbent.
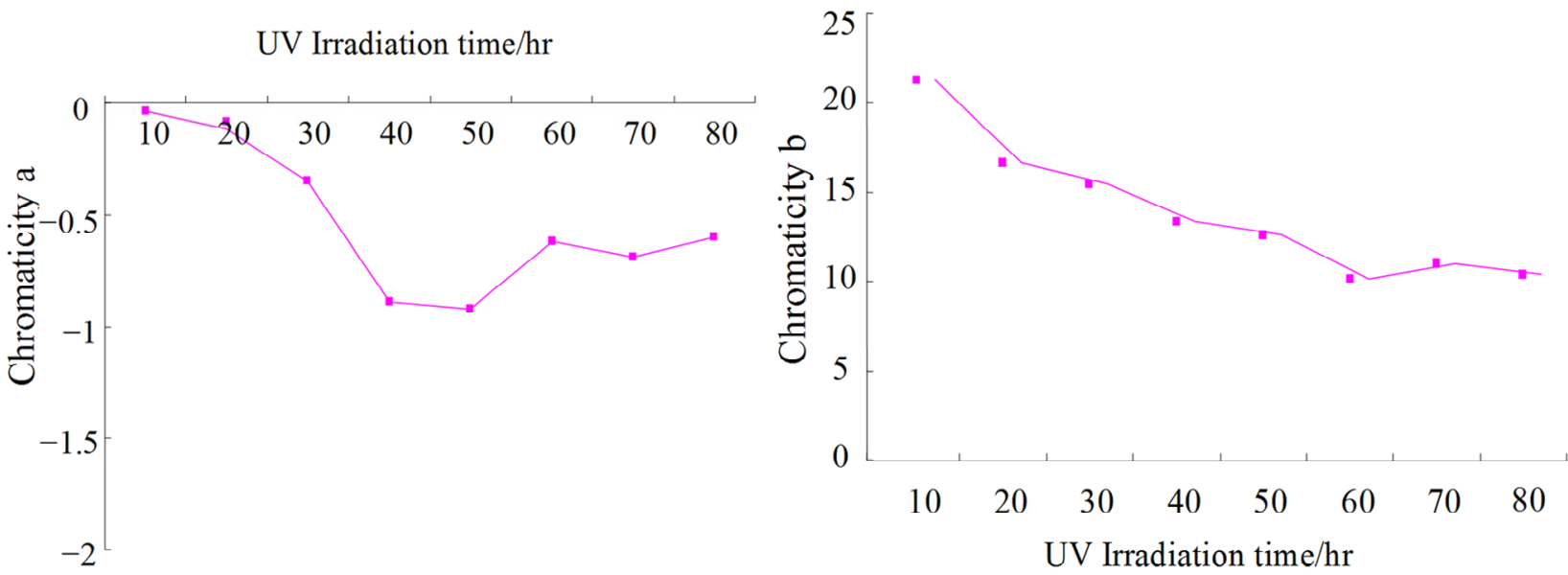

Figure 4. Variation of chromaticity a and b with UV Irradiation time. 


\subsection{Changes of Physicochemical Properties of Lacquer Wax Before and after Decoloration}

Chemical constituents of the lacquer wax were analyzed by GC-MS, and the Changes of physicochemical properties of lacquer wax were showed before and after discoloration in Tables $\mathbf{4}$ and $\mathbf{5}$.

In the process of physical discoloration, the chemical constituents and their relative contents of fatty acids had not change significantly, the TSFA, TUSFA and TDBA all just had a subtle reduce, and the difference was the relative contents of palmitic acid, oleic acid and eicosanebioic acid, which attributed more to the decrease of free acids adsorbed by the adsorbent. Physical properties of melting point did not change obviously yet. Physical properties of M.P didn't change marketly yet, however A.V, I.V, P.V and S.V slightly decreased after decoloration. i.e., A.V changed from 88.27 to 83.7 , I.V from 33.62 to 30.02 , P.V from 8.78 to 4.41 , and S.V from
213.10 to 210.66 .

Compared to unbleached lacquer wax, UV irradiation had a significant effect on its physicochemical properties. It not only changed the relative content of fatty acids, but also decreased TUSFA from $19.617 \%$ to $11.022 \%$, and TDBA from $4.379 \%$ to $2.017 \%$, in the meantime, the relative content of TSFA could be raised from $76.462 \%$ to $86.077 \%$ after $60 \mathrm{hr} \mathrm{UV}$ irradiation time. As UV light could provide energy for unsaturated carbon-carbon double bonds or hydrocarbon double bonds, so the longer the UV irradiation time last, the more serious the unsaturated double bonds could be oxided into some epoxides, peroxides, alcohols, ketones, aldehydes, or carboxylic acids et al., this is the key reason why the P.V could be rised very obviously from 8.78 to 207.26 . With the reduce of TUSFA, the I.V and A.V clearly declined from 33.62 to 10.02 , and from 88.27 to 81.31 , respectively. However M.P just slightly rised.

Table 4. Changes of physicochemical properties of lacquer wax by physical adsorption.

\begin{tabular}{|c|c|c|c|c|}
\hline No. & \multicolumn{2}{|c|}{ relative contents of the fatty acids } & \multirow{2}{*}{$\begin{array}{l}\text { A (\%) } \\
0.904\end{array}$} & \multirow{2}{*}{$\begin{array}{l}\mathrm{B}(\%) \\
0.858\end{array}$} \\
\hline 1 & Myristic acid, & $\mathrm{C} 14: 0$ & & \\
\hline 2 & Pentadecanoic acid, & $\mathrm{C} 15: 0$ & 0.437 & 0.221 \\
\hline 3 & Hexadecenoic acid, & $\mathrm{C} 16: 1$ & 0.223 & 0.189 \\
\hline 4 & Palmitic acid, & $\mathrm{C} 16: 0$ & 59.743 & 57.538 \\
\hline 5 & Heptadecanoic acid, & $\mathrm{C} 17: 0$ & 0.608 & 0.602 \\
\hline 6 & Linoleic acid, & $\mathrm{C} 18: 2$ & 0.818 & 0.968 \\
\hline 7 & Oleic acid, & $\mathrm{C} 18: 1$ & 14.197 & 15.265 \\
\hline 8 & Stearic acid, & $\mathrm{C} 18: 0$ & 11.409 & 12.981 \\
\hline 9 & Hexadecanedioic acid, & $\mathrm{C} 16 \mathrm{~d}+$ & 0.828 & 0.592 \\
\hline 10 & Eicosanoic acid, & $\mathrm{C} 20: 0$ & 1.731 & 1.527 \\
\hline 11 & Eicosanebioic acid, & $\mathrm{C} 20 \mathrm{~d}+$ & 2.712 & 2.045 \\
\hline 12 & Docosanedioic acid, & $\mathrm{C} 22 \mathrm{~d}+$ & 0.839 & 0.624 \\
\hline 13 & Docosanoic acid, & $\mathrm{C} 22: 0$ & 1.630 & 1.619 \\
\hline 14 & Total saturated fatty acids & (TSFA) & 76.462 & 75.346 \\
\hline 15 & Total unsaturated fatty acids & (TUSFA) & 19.617 & 19.683 \\
\hline \multirow[t]{2}{*}{16} & Total dibasic acids & (TDBA) & 4.379 & 3.261 \\
\hline & \multicolumn{2}{|c|}{ Physical properties } & A & B \\
\hline 17 & \multicolumn{2}{|c|}{ Melting point (M.P), ${ }^{\circ} \mathrm{C}$} & 51.02 & 50.20 \\
\hline 18 & \multicolumn{2}{|c|}{ Acid value (A.V), KOH, mg/g, } & 88.27 & 83.7 \\
\hline 19 & \multicolumn{2}{|c|}{ Iodine value (I.V), D/g/100 g } & 33.62 & 30.02 \\
\hline 20 & \multicolumn{2}{|c|}{ Peroxide value (P.V), $\mathrm{mmol} / \mathrm{kg}$} & 8.78 & 4.41 \\
\hline 21 & \multicolumn{2}{|c|}{ Saponification value (S.V), $\mathrm{KOH}, \mathrm{mg} / \mathrm{g}$} & 213.10 & 210.66 \\
\hline
\end{tabular}

A and B represented before and after decoloration of lacquer wax, respectively. 
Table 5. Changes of physicochemical properties of lacquer wax during UV irradiation.

\begin{tabular}{|c|c|c|c|c|c|c|c|}
\hline \multirow{2}{*}{ No. } & \multirow{2}{*}{\multicolumn{2}{|c|}{ chemical properties }} & \multicolumn{5}{|c|}{ Relative contents of the fatty acids (\%) } \\
\hline & & & A & $\mathrm{C}$ & $\mathrm{D}$ & $\mathrm{E}$ & $\mathrm{F}$ \\
\hline 1 & Myristic acid, & $\mathrm{C} 14: 0$ & 0.904 & 0.935 & 1.002 & 1.373 & 1.476 \\
\hline 2 & Pentadecanoic acid, & $\mathrm{C} 15: 0$ & 0.437 & 0.452 & 0.477 & 0.535 & 0.627 \\
\hline 3 & Hexadecenoic acid, & C16:1 & 0.223 & 0.116 & 0.0161 & 0 & 0 \\
\hline 4 & Palmitic acid, & $\mathrm{C} 16: 0$ & 59.743 & 62.167 & 62.435 & 63.047 & 63.184 \\
\hline 5 & Heptadecanoic acid, & $\mathrm{C} 17: 0$ & 0.608 & 0.754 & 0.897 & 0.914 & 1.061 \\
\hline 6 & Linoleic acid, & $\mathrm{C} 18: 2$ & 0.818 & 0.360 & 0.112 & 0 & 0 \\
\hline 7 & Oleic acid, & $\mathrm{C} 18: 1$ & 14.197 & 13.982 & 12.495 & 10.225 & 9.005 \\
\hline 8 & Stearic acid, & C18:0 & 11.409 & 13.131 & 13.358 & 14.375 & 14.642 \\
\hline 9 & Hexadecanedioic acid, & $\mathrm{C} 16 \mathrm{~d}+$ & 0.828 & 0.761 & 0.693 & 0.611 & 0.585 \\
\hline 10 & Eicosanoic acid, & $\mathrm{C} 20: 0$ & 1.731 & 1.801 & 2.554 & 2.836 & 3.183 \\
\hline 11 & Eicosanebioic acid, & $\mathrm{C} 20 \mathrm{~d}+$ & 2.712 & 2.286 & 1.664 & 1.343 & 1.043 \\
\hline 12 & Docosanedioic acid, & $\mathrm{C} 22 \mathrm{~d}+$ & 0.839 & 0.636 & 0.518 & 0.466 & 0.389 \\
\hline 13 & Docosanoic acid, & $\mathrm{C} 22: 0$ & 1.630 & 1.727 & 1.793 & 1.832 & 1.904 \\
\hline 14 & Total saturated fatty acids & (TSFA) & 76.462 & 79.166 & 82.516 & 84.912 & 86.077 \\
\hline 15 & Total unsaturated fatty acids & (TUSFA) & 19.617 & 18.141 & 15.498 & 12.645 & 11.022 \\
\hline \multirow[t]{2}{*}{16} & Total dibasic acids & (TDBA) & 4.379 & 3.683 & 2.875 & 2.42 & 2.017 \\
\hline & \multicolumn{2}{|c|}{ Physical properties } & A & $\mathrm{C}$ & $\mathrm{D}$ & E & $\mathrm{F}$ \\
\hline 17 & \multicolumn{2}{|c|}{ Melting point (M.P), ${ }^{\circ} \mathrm{C}$} & 51.02 & 51.10 & 51.5 & 51.8 & 52.4 \\
\hline 18 & \multicolumn{2}{|c|}{ Acid value (A.V), $\mathrm{KOH}, \mathrm{mg} / \mathrm{g}$, } & 88.27 & 87.34 & 84.39 & 83.69 & 81.31 \\
\hline 19 & \multicolumn{2}{|c|}{ Iodine value (I.V), $\mathrm{D} / \mathrm{g} / 100 \mathrm{~g}$} & 33.62 & 13.05 & 12.48 & 11.51 & 10.02 \\
\hline 20 & \multicolumn{2}{|c|}{ Peroxide value (P.V), $\mathrm{mmol} / \mathrm{kg}$} & 8.78 & 112.14 & 173.50 & 191.69 & 207.26 \\
\hline 21 & \multicolumn{2}{|c|}{ Saponification value (S.V), $\mathrm{KOH}, \mathrm{mg} / \mathrm{g}$} & 213.10 & 210.56 & 209.47 & 208.88 & 208.37 \\
\hline
\end{tabular}

A, C, D, E and F: irradiation time of lacquer wax by UV light for 0, 20, 40, 60 and 80 hours, respectively.

During UV irradiation, from the analysis of Py-GC/ MS, some epoxy was tracked, carbon-carbon double bonds or hydrocarbon double bonds would be destroyed by oxidation, some smaller organic acid and the corresponding ketone and diacid were detected, it directly led the discoloration of lacquer wax and changed the physicochemical properties of lacquer wax. However the mechanism of UV irradiation is not clear yet, it needs further to study.

\section{CONCLUSIONS}

Showafuku cultivar has been used to make Japan wax from the berries of of Rhus succedanea $L$, while lacquer wax from berries of $\mathrm{T}$. verniciflua in China has different physicochemical properties compared with Japan wax due to the factors of cultivars, growing environment, and lacquer tapping etc., so Japan wax is distinct from China lacquer wax.

Discoloration methods by physical adsorption, chemical and UV irradiation are common in the processing industry of oil and fatty. Colors of lacquer wax are mainly composed of green chlorophyll, red carotene and yellow xanthophyll. Japan wax is usually extracted by the compression method and the sun's ray, adsorbents or chemical agents are used to decolorize and bleach it. Adsorbents, such as activated charcoal or acid clay, are used in different ways, while it usually takes 20 days for sunlight irradiation.

This investigation obtained better discoloration technology. Adsorbents used in this physical process were activated carbon-kieselguhr $=3: 2(\mathrm{~g} / \mathrm{g})$, which were more cheaply and widely used in industry. Optimal conditions chosed petroleum ether as solvent, solid-liquid 
ratio of raw lacquer wax to petroleum ether $1: 20(\mathrm{~g} / \mathrm{mL})$, ad-sorbent accounted for $5 \%$ weight of raw lacquer wax, kept a temperature of $80^{\circ} \mathrm{C}$ for $30 \mathrm{~min}$, twice. Besides, UV irradiation was also present as a good method to decolour lacquer wax, which could get a similar discoloration effect compared to the physical adsorption. UV irradiation for 60 hours could achieve a good discoloration at $60^{\circ} \mathrm{C}$. It is believed that UV irradiation will serve as an alternative and effective discoloration method in fu- ture. In conclusion, UV irradiation is a simple and con- venient method, it can not only can bleach lacqer wax, but also changes the physicochemical properties of lacquer wax. However, the mechanism of UV irradiation and the intermediates of peroxides will be investigated in the future.

\section{ACKNOWLEDGEMENTS}

The authors thank very much Prof. S. Noshiro from Japan Forestry and Forest Product institute for him to provide the refined Japan wax and modified Japan wax (Star Cherry) from Araki wax co. The financial support of this work is also gratefully acknowledged by the National "Twelfth Five-Year" Plan for Science \& Technology Support (No. 2012BAD36B00) and international cooperation programme "No. 0S2012GR0138" as well as 948 programme (2012-4-05).

\section{REFERENCES}

[1] Lu, R., Kanamori, D. and Miyakoshi, T. (2011) Characterization of thitsiol dimer structures from melanorrhoea usitata with laccase catalyst by NMR spectroscopy. International Journal of Polymer Analysis and Characterization, 16, 86-94. doi:10.1080/1023666X.2011.541030

[2] Jefferson, A. and Wangchareontrakul, S. (1986) Long chain phenols: Urushiol, laccol, thitsiol and phenylalkyl catechol compounds in Burmese lac from Melanorrhoea usitata. Journal of Chromatography, 367, 145-154.

[3] Dong, Y.H., Wang, C.Z. and Gong, K. (2009) Research progress on chemical constituents and comprehensive application of lacquer trees. Indian Journal of Science and Technology, 29, 225-232.
[4] Tsuji, S., Tonogai, Y., Ito, Y. and Harada, M. (1985) General analysis of various natural waxes in cosmetics. Journal of Society of Cosmetic Chemists of Japan, 192, 79-89. doi: $10.5107 /$ sccj. 19.79

[5] Meguro, S. and Kawachi, S. (1989) Some physical properties of haze wax correlated with major fatty acids. Journal of the Japan Wood Research Society, 358, 754760

[6] Meguro, S. and Kawachi, S. (1990) Major fatty acid contents of haze wax. Changes during the growth and storage periods of haze seeds. The Japan Wood Research Society, 362, 133-138

[7] Wang, C.Z. and Wang, Q.F. (2000) Physical and chemical characteristics and chemical composition of urushi wax (oil). Chinese Wild Plant Resources, 19, 35-37

[8] Wang, Y.Q., Zhang, F.X. and Zhao H. (2003) Factors influencing colour of urushi wax. Chemistry and Industry of Forest Products, 23, 81-83

[9] Tachibana, S., Sakuragi, M. and Sumimoto, M. (1989) Chemical conversion of extractives for the production of chemicals and fuels. III. Sunlight bleaching of urushi wax. Nippon Mokuzai Gakkaishi, 35, 356-361

[10] Dal, K.Y., Hong, K.N., Dong, S.K. and Witoon, P. (2008) Decoloration of chitosan by UV irradiation. Carbohydrate Polymers, 73, 384-389. doi:10.1016/j.carbpol.2007.12.003

[11] Meguro, S. and Kawachi, S. (1989) Some physical properties of haze wax correlated with major fatty acids. Journal of the Japan Wood Research Society, 35, 754-760.

[12] Meguro, S. and Kawachi, S (1990) Major fatty acid contents of haze wax. Changes during the growth and storage periods of haze seeds. Journal of the Japan Wood Research Society, 36, 133-138

[13] Xu, J. and Kawachi, S. (1989) Seasonal variations of some biochemical constituents in hazenoki, Rhus succedanea. Journal of the Japan Wood Research Society, 35, 30-35.

[14] Zhao, W.E. (2003) The antioxidant properties of carotenoids. Journal of Zhengzhou University. Natural Science Edition, 24, 38-46. 